\title{
Os sentidos: jardins e paisagens
}

\author{
SCHIRLEY FÁTIMA NOGUEIRA DA SILVA CAVALCANTE ALVES(1) e PATRÍCIA DUARTE DE OLIVEIRA PAIVA(2)
}

\begin{abstract}
RESUMO
Os sentidos permitem aos seres vivos a capacidade de perpecepção, principalmente de características do meio ambiente, por meio de sensações de origem interna ou externa. Até a algum tempo, apenas se relacionava a jardins e paisagens os cinco sentidos básicos: visão, audição, olfato, tato e gosto. Mas, com a evolução do conceito da paisagem, também se aumentou a abrangência dos seus sentidos, indo além desse conjunto das sensações humanas, sendo incluídas também as relações sociais, culturais e econômicas. Os jardins e paisagens passam a se manifestar como um conjunto de representações estruturadas e caracterizadas por forte impregnação emocional e cultural, desencadeando no homem sensações nascidas da relação entre sua trajetória histórica e cultural.

Palavras-chave: jardim, sentidos, sensações, paisagem, paisagismo.
\end{abstract}

\section{ABSTRACT}

The senses: gardens and landscapes

The senses allow the living being the capacity of perception, especially environmental characteristics, through senses of internal or external origins. Until recently gardens and landscapes were only related to the five basic senses: vision, hearing, smell, touch, and taste. However, with the evolution of the landscape concept, the range of the senses was increased beyond the set of these human sensations, including also social, cultural and economic relations. Gardens and landscapes turn into a group of structured representations characterized by a strong emotional and cultural impregnation, unchaining in humans sensations originated from the relation between their historical and cultural path.

Keywords: garden, sense, sensations, landscape, landscape design.

\section{INTRODUÇÃO}

A questão dos sentidos nos jardins e nas paisagens: explanar essa complexa relação física, estética e sensorial, entre o homem e seu meio, realçando suas manifestações sensoriais, é um prazer e, ao mesmo tempo, um desafio. Mergulhar na paisagem, se deixar envolver pela atmosfera terrestre, sentir a natureza, aguçar os sentidos ao percorrer um jardim, contemplar uma paisagem, deixar aflorar os profundos sentimentos.

Tanto os jardins, espaços elaborados; como as paisagens, entidades simbólicas, desencadeiam no homem sensações nascidas da relação entre sua trajetória histórica e cultural. Essa experiência transcorre gerando percepções e emergindo sentimentos de surpresa, bem estar, saudades, melancolia, alegria..., e tantos outros. A arte dos jardins se sustenta nessa introspecção, e se expressa por meio da estética e dos valores simbólicos das paisagens, criando estruturas físicas dessas metáforas.

A evolução do conceito da paisagem aumentou a abrangência dos seus sentidos, indo além do conjunto das sensações humanas, cingindo as relações sociais, culturais e econômicas, desenvolvidas dentro desse grande contexto. Os jardins passam a se manifestar como um conjunto de representações estruturadas e caracterizadas por forte impregnação emocional e cultural, determinando uma relação de interação comportamental e de idealização da natureza, instigando a percepção da paisagem nas atitudes, sonhos e comportamentos dos indivíduos.

\section{SENTIDOS E PERCEPÇÕES}

Sentidos são os meios através dos quais os seres vivos e percebem e reconhecem outros organismos e as características do meio ambiente em que se encontram, por meio de sensações de origem interna ou externa (FERREIRA, 2008). Os sentidos podem significar, ainda, propósito ou objetivo. Dessa forma, a atribuíção de um significado explicita um sentimento e uma relação.

A percepção é o mecanismo mais importante que relaciona o homem ao ambiente. As pessoas experimentam o meio ambiente através dos sentidos (DEL RIO e OLIVEIRA, 1999). Os sentidos também são referidos como funções orgânicas que buscam o prazer sensual e que denotam sensualidade. Entre as diversas entidades espaciais construídas dentro de um sistema simbólico, científico ou sócio-cultural, a paisagem constitui um espaço percebido e se define como uma entidade construída e

(1) Pós-doutoranda, bolsista FAPEMIG, Departamento de Agricultura/DAG, UFLA, sfnsca@terra.com.br.

(2) Professora, Dra., Departamento de Agricultura/DAG, UFLA patriciapaiva@dag.ufla.br. 
simbólica (COLLOT, 1990). O jardim, enquanto idealização da natureza, se define dentro desse momento histórico como uma representação metafórica da paisagem, se desenvolvendo dentro da temática da arte contemporânea, instigando e interpelando sobre as mais variadas sensações.

\section{PAISAGEM E BEM ESTAR}

Existe uma relação estreita entre os diversos sentidos e a paisagem, que não reduz a qualidade da paisagem à estética das formas percebidas pela visão, se estendendo ao conjunto dos cinco sentidos (LUGINBUHL, 2006).

Nesse contexto, fica claro que, além da imagem, os fatores auditivos, odoríferos, táteis e gustativos compõem a gama da satisfação corporal. A sonoridade do lugar pode criar uma sensação de bem estar ou de mal estar, tanto do ponto de vista qualitativo, dependendo do tipo de sonoridade; quanto do ponto de vista quantitativo: nível de sonoridade.

Os miasmas, emanação mefítica, termo muito comum nos relatos dos viajantes do século XIX, decorrentes da falta de cuidado com o meio ambiente dentro da cadeia de uma atividade, podem causar aversão a uma bela paisagem, criando patologias na mesma que, para serem sanadas, precisam envolver ações de transformação ambiental, cultural e social.

Ao contrário, percorrer uma plantação de laranjas ou um cafezal, durante o período de sua floração, traz uma sensação de extremo bem estar. Ao percorrer uma paisagem pode-se associar a experiência tátil à gustativa, provando os produtos da terra, um prazer pessoal de conseqüências interessantes quanto à valorização e a sustentabilidade de uma cultura do "savoir-faire" (=saber fazer).

Num contexto mais global, o cuidado com o meio ambiente pode amenizar os grandes contrastes das sensações térmicas, que nem sempre trazem a sensação de bem estar. A sombra de uma árvore no verão dos trópicos traz consigo uma das sensações mais agradáveis dessa época do ano. Mergulhar em uma água limpa, beber uma água potável que aflora da terra, são luxos de algumas paisagens naturais que formam um patrimônio natural, que devem ser reconhecidos e preservados.

Burle Marx (1987) acreditava que os jardins eram uma forma de sensibilização da importância dessa preservação da paisagem na cultura da sociedade predatória brasileira. Essa integração da preocupação ambiental na organização do espaço desenvolveu o conceito que Pilloto (2003) chama de Paisagismo Ecológico, definindo-o como a arte de criar, recriar, modificar ou recuperar paisagens que contribuam para a qualidade de vida do homem, sem desrespeitar o meio ambiente.

\section{OS SENTIDOS NOS JARDINS}

Os jardins sempre aproveitaram o sentido da visão na sua formulação, desde o plantio em alinhamento de árvores dos jardins da Antiguidade, passando pela contemplação da paisagem dos vales a partir dos terraços dos jardins italianos ou, ainda, pela criação das grandes perspectivas do jardim francês e do enquadramento do olhar no jardim pitoresco. Os jardins, espaço de experiência sensível, se desenvolveram assentados basicamente no sentido da visão, salpicados nessa trajetória temporal com alguns toques sonoros.

Atualmente, os outros sentidos ganharam maior interesse, gerando uma forte apelação sensível, abrangendo conotações poéticas que os instigam e atingem outras dimensões. A arte visual, tema que sempre regeu a sinfonia da criação dos jardins, passa a ser complementada com o apelo aos outros sentidos a partir do final do século XX. Da sonoridade da água nos jardins romanos, à mostra científica da propagação do som no Parque La Villette, ou ainda a intervenção sonora de ambientes selvagens no jardim do Museu da Arte Bruta do Quais Branly, em Paris. Os sentidos passaram a ser empreendidos como complemento das mais variáveis temáticas, como um refinamento dos mais variados contextos, desde temas contemporâneos já citados até os mais clássicos, como no caso do Roseiral Santa Giustina em Pádua na Itália que, além de toda sua concepção baseada na interação da rosa com os sentidos da visão, olfato, tato e paladar, evoca a evolução histórica das variedades das roseiras e é banhado por uma intervenção musical elaborada a partir de uma coletânea de músicas clássicas dedicadas às rosas.

Dessa maneira percebe-se que os jardins contemporâneos tiram proveito das sensações com o objetivo de aproximar o homem de sua essência, criando cenários envolventes, onde sons da natureza, o sabor e o odor das mais diversas ervas condimentares, medicinais e mesmo aromáticas, além das tradicionais estruturas como pomares e hortas passam a atuar como elementos estimuladores da inter-relação entre o homem e a natureza.

Os chamados jardins sensoriais se desenvolveram a partir da necessidade de uma inclusão mais direta de pessoas portadoras de limitação física, especificamente para os cegos e cadeirantes. A forma evidente e pedagógica do modelo de concepção desses jardins que apresentam adequação de equipamentos, sinalizações e vegetação que interagem de forma mais incisiva com seus usuários acabou se transformando na inclusão do prazer da experiência e do contato sensível com a natureza dos mais diversos grupos sociais.

Além dos cinco sentidos explorados na épica da concepção dos jardins, tem-se ainda, o sexto sentido, que se refere à percepção intuitiva, uma espécie de aura que transcende o campo de intervenção, criando um fio condutor que traduz esses lugares e permitem captar e interpretar sua essencia. Abordar o espírito dos lugares na concepçao de jardins se tornou uma maneira de mostrar ao público o eixo da experiencia global da paisagem dentro do contexto do jardim (VIEL, 2008).

\section{CONCLUSÕES}

A evolução da paisagem entrelaçou em seu conceito os mais variados sentidos, ganhando uma concepção diversificada e criando inúmeras formas de conhecimento, passando a designar novas questões de ordem patrimonial, econômica, social e cultural. A paisagem, esse paradigma de mediação entre espaço e sociedade apreende novos valores e ganha 
outros sentidos, como o de ordem patrimonial e de indicador econômico e qualitativo.

Na elaboração e concepção dos jardins contemporâneos, os sentidos se transformam em um apelo para elaborações cada vez mais finas e sutis que se comprometem a sensibilizar o homem moderno dos prazeres provenientes de sua relação com a natureza, criando cenários cada vez mais elaborados e interativos.

\section{REFERÊNCIAS}

ALVES, S.F.N.S.C.; REIS, S.N.; PAIVA, P.D.O. ColetâneaSimpósios de paisagismo 2002-2008. Lavras: Editora UFLA, 2009. 231p.

BURLE-MARX, R. Arte e paisagem - conferências escolhidas. São Paulo: Livraria Nobel, 1987. 103p.

COLLOT, M. Pontos de vista sobre a percepção das paisagens. Boletim de Geografia Teórica. Rio Claro. Tradução: Lineu Bley e Lucy Marion C. P. Machado, v. 20, n. 39, 1990, p. 21 32.
FERREIRA, A.B.H. Aurélio - o dicionário da língua portuguesa. Curitiba: Editora Positivo, 2008.

LUGINBUHL, Y. Paysage et bien-être individuel e social. In : Direction de la Communication du Conseil de l'Europe. Paysage et développement durable: les enjeux de la Convention Européenne du paysage. Strasbourg, Ed. Conseil de l'Europe, 2006, p. 31-55.

PILOTTO, J. Cidade verde: uma ferramenta ecológica. Florianópolis, Universidade Federal de Santa Catarina, 2003. 156p. (Tese de doutorado).

SILVA, A.T.; TAVARES, T.S.; PAIVA, P.D.O.; NOGUEIRA, D.A. As praças Dr. Augusto Silva e Leonardo Venerando Pereira, Lavras-MG, segundo a visão dos seus freqüentadores. Ciência e Agrotecnologia, Lavras, v.32, n.6, p.1701-1707, 2008.

VIEL, A. Quand souffle l'esprit des lieux. 2008. Disponível em: $\quad<$ http://www.international.icomos.org/quebec2008/cd/ toindex/78_pdf/78-B3X3-152.pdf>. Acesso em 10/04/2009. 